\title{
Perceptions of Community on Post-Contraceptive Care by Primary Health Care System in Tribal and Rural Areas of Visakhapatnam District of Andhra Pradesh
}

\author{
G.R. Varma and A. Rohini \\ Department of Social Work, School of Distance Education, Andhra University, \\ Visakhapatnam 530 003, Andhra Pradesh, India \\ Telephone: +8912754966 (Office), 2539078 (Home) \\ E-mail: anamrohini@gmail.com
}

KEYWORDS Family planning; post-contraceptive care: primary health care; tribal; rural; Andhra Pradesh

\begin{abstract}
The present paper reports the perceptions of community on post-contraceptive care provided by the staff of primary health care system among tribal and rural population of Andhra Pradesh, India. The study has been conducted in two tribal and two rural primary health centres of Visakhapatnam district of Andhra Pradesh. Quantitative data were collected from married women of the age up to 40 years. Qualitative data through in-depth interviews with key-informants were also collected. The predominant contraception method among both tribal and rural areas was female sterilization, i.e., tubectomy. The government institutions were the main source of contraception in both tribal and rural areas. Though, the quality of pre and post contraception care among the community is very important, the perceptions of the community on post-contraception care were not at desirable levels. These findings emphasise the continuing need to strengthen post-operative care and counselling for sterilization acceptors. These indicators of contraceptive service outreach were poor among scheduled tribe population and situation was not fair in rural areas also. Thus, the centralized top-down planning of healthcare services could not facilitate the tribal and rural people to articulate needs for services.
\end{abstract}

\section{INTRODUCTION}

Despite aggressive efforts of government in promoting family planning, the 2001 census data showed that India continued to have one of the most rapidly growing populations in the world. The heavy centralization of India's family planning programmes often prevents due consideration from being given to regional differences. Centralization is encouraged to a large extent by reliance on central government funding. As a result, many of the goals and assumptions of national population control programs do not correspond exactly with local attitudes toward birth control. Studies have found that most couples in fact regard family planning positively. However, the common fertility pattern in India diverges from the twochild family that policy makers hold as ideal. Women continue to marry young, in the mid-

Address for correspondence:

Dr. A. Rohini

Associate Professor of Social Work

School of Distance Education, Andhra University, Visakhapatnam 530 003, Andhra Pradesh

Telephone: +8912754966 (Office), 2539078 (Home)

E-mail: anamrohini@gmail.com 1990s, the average age at marriage is just over eighteen years. On average, those accepting sterilization already have four living children, of whom two are sons. The strong preference for sons is a deeply held cultural ideal based on economic roots. As majority of rural and tribal population heavily depend on government sector and massive effort to reduce fertility is one of the functions of district health system. The quality of pre and post contraceptive care usually determines the acceptance of contraception by the community. The present paper reports the communities' acceptance of and perceptions on post-contraceptive care provided by district health system among tribal and rural population of Andhra Pradesh, India.

\section{MATERIALS AND METHODS}

The present study was undertaken in four primary health centre (PHC) areas (Minimuluru and Hukumpet from tribal area and Atchuthapuram and Chuchukonda from rural area) of Visakhapatnam district of Andhra Pradesh. From each PHC area, the PHC village was selected. All health sub-centre (HSC) villages and villages having no health institution (PHC or HSC) were 
listed separately for each PHC. From the list, two HSC villages and three villages having no health institution per each $\mathrm{PHC}$ were selected randomly. Thus 24 villages (4 PHC villages, $8 \mathrm{HSC}$ villages and 12 villages with no health institution) were sampled. Both quantitative and qualitative research methods were employed. The quantitative data were collected through interview using a schedule with married women up to the age of 40 years on contraception services. The age of 40 years was fixed as cut-off point, as women of these tribal and rural areas complete the reproductive events before attaining the age of 40 years (Padmadas et al., 2004). The questionnaire was designed to collect the details of utilization of and perceptions on post-contraception services. To undertake the above quantitative survey, five random points were identified in each village to cover all areas of the village, after mapping the village. At each random point, three houses located at three random directions were identified and three women from these houses were sampled. If a woman was absent or not available in that house, a woman from the next house was selected to obtain at least 15 women from each village. In some villages, one or two women were sampled more to maintain the minimum sample size with the assumption that some women were to be excluded due to incompleteness of the information. However, no sample was excluded due to incompleteness of the data.

The qualitative data were collected through in-depth interviews with key-informants in the villages $(n=12)$ with regard to utilization of services related to contraception. The key informants are defined as individuals who possess special knowledge and who are willing to share their knowledge with the researcher and are included village head/leader, members of local administrative bodies, teachers, etc. During the selection of key informants the guideline of Spradley (1979) and Hudelson (1994) were followed. In-depth interviews were conducted by following Pelto and Pelto (1978) and Lengeler et al. (1991). The quantitative data were analysed through SPSS 10.0 (SPSS Inc. Chicago, IL, USA) and the qualitative data were computerized through a word processor and analysed through Atlas/Ti (Scientific Software Development, Berlin, Germany).

\section{RESULTS}

The data pertaining to utilization of family planning services were obtained by interviewing 180 tribal women and 195 rural married women of up to 40 years of age. Distribution of women based on the methods of contraception used was shown in Table 1. Data indicated that tubectomy was a predominantly used method of contraception among both tribal (55.6 per cent) and rural women (77.9 per cent). Vasectomy was practiced among small proportion of people (14.4 per cent of tribal and 5.1 per cent of rural respondents). The difference between tribals and rurals was significant $(p<0.001)$. In both tribal $(83.72 \%)$ and rural areas (68.67\%), women have received contraception service from PHC or HSC (Table 2). It was followed by government health institution in near by towns among both tribal (13.18\%) and rural areas (19.28\%). Private health institutions and government camps serve as source of contraception for small proportion of people. The key informant also recorded that people in these study areas (both tribal and rural area) prefer PHCs or government hospitals in nearby towns. In rural areas, few people prefer private clinics for contraception services.

Table 1: Distribution of women based on the methods of contraception

\begin{tabular}{lrrrr}
\hline $\begin{array}{l}\text { Method of } \\
\text { contraception }\end{array}$ & \multicolumn{2}{l}{ Tribal $(n=180)$} & & Rural $(n=195)$ \\
\cline { 2 - 3 } \cline { 5 - 5 } & No. & $(\%)$ & No. & $(\%)$ \\
\hline Vasectomy & 26 & $(14.4)$ & 10 & $(5.1)$ \\
Tubectomy & 100 & $(55.6)$ & 152 & $(77.9)$ \\
Oral pills & 1 & $(0.6)$ & 0 & $(0.0)$ \\
$\begin{array}{l}\text { Condoms } \\
\text { Not used /using any }\end{array}$ & 2 & $(1.1)$ & 4 & $(2.1)$ \\
$\quad$ contraception & 51 & $(28.3)$ & 29 & $(14.9)$ \\
& & & & \\
$\chi^{2}$ for difference between tribal and rural population \\
$=23.47, p<0.001$
\end{tabular}

Table 2: Distribution of women based on source of contraception service

\begin{tabular}{|c|c|c|c|c|}
\hline \multirow{2}{*}{$\begin{array}{l}\text { Source of } \\
\text { contraception } \\
\text { service* }\end{array}$} & \multicolumn{4}{|c|}{ Tribal $(n=129)$ Rural $(n=166)$} \\
\hline & No. & $(\%)$ & $\overline{N o}$. & $(\%)$ \\
\hline PHC / HSC & 108 & $(83.7)$ & 114 & $(68.7)$ \\
\hline Government camps & 1 & $(0.8)$ & 2 & $(1.2)$ \\
\hline $\begin{array}{l}\text { Government institut- } \\
\text { ions in nearby towns }\end{array}$ & 17 & $(13.2)$ & 32 & (19.3) \\
\hline $\begin{array}{l}\text { Private health } \\
\text { institutions }\end{array}$ & 3 & $(2.3)$ & 14 & $(8.4)$ \\
\hline Others & 2 & (1.6) & 4 & $(2.4)$ \\
\hline
\end{tabular}

*Multiple responses are given. PHC=primary health centre, HSC=health sub-centre

$\chi^{2}$ for difference between tribal and rural population $=8.87, p>0.05$ 
Table 3: Distribution of women based on reception of follow-up visits of health worker after sterilization

\begin{tabular}{lccc}
\hline Follow-up & Tribal & Rural & Total \\
visit of & $(n=126)$ & $(n=162)$ & $(n=288)$ \\
\cline { 2 - 3 }
\end{tabular}

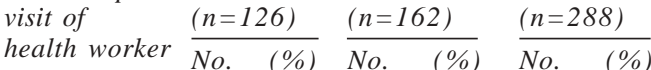

Yes $\quad 104(82.54) \quad 109(67.28) 213(73.96)$

$\begin{array}{lllll}\text { No } & 22(17.46) & 53(32.72) & 75 & (26.04)\end{array}$

$\chi^{2}$ for difference between tribal and rural population $=8.56, p<0.01$

Table 4: Distribution of women based on their rating of follow-up visits of health workers after sterilization

\begin{tabular}{|c|c|c|c|}
\hline \multirow{2}{*}{$\begin{array}{l}\text { Rating of pre } \\
\text { and post inter- } \\
\text { vention care }\end{array}$} & $\begin{array}{c}\text { Tribal } \\
(n=126)\end{array}$ & $\begin{array}{c}\begin{array}{c}\text { Rural } \\
(n=162)\end{array} \\
\end{array}$ & $\begin{array}{l}\text { Total } \\
(n=288)\end{array}$ \\
\hline & No. (\%) & No. $\quad(\%)$ & No. \\
\hline Excellent & $9 \quad(7.14)$ & $7 \quad(4.32)$ & $16 \quad(5.56)$ \\
\hline Good & $55(43.65)$ & $35(21.60)$ & $90(31.25)$ \\
\hline Alright & $35(27.78)$ & $45(27.78)$ & $80(27.78)$ \\
\hline $\begin{array}{l}\text { Not satis- } \\
\text { factory }\end{array}$ & $5 \quad(3.97)$ & $22(13.58)$ & $27 \quad(9.38)$ \\
\hline $\begin{array}{c}\text { Health worker } \\
\text { not visit }\end{array}$ & $22(17.46)$ & $53(32.72)$ & $75(26.04)$ \\
\hline
\end{tabular}

The pre and post contraception care is important particularly for those who undergoes permanent sterilization. It is expected that this care has to be provided by the health workers during their regular visits to the village. Out of the total persons undergone permanent sterilization (126 tribal and 162 rural respondents), $82.54 \%$ of tribal households and $67.28 \%$ of rural households were visited by health workers (Table 3 ). Remarkably higher proportion of rural women $(32.72 \%)$ than tribal women $(17.46 \%)$ reported that health workers were not visited to their houses. The tribal-rural difference with regard to follow up visits of health worker after sterilization was significant $(\mathrm{p}<0.01)$. The women were probed to rate the follow up visits of health worker after sterilization and the results are summarised in Table 4. Remarkably higher proportion of rural women $(32.72 \%)$ than tribal women $(17.46 \%)$ reported that health workers have not visited to their houses. In tribal area, majority of women perceived these follow up visits as good $(43.65 \%)$, followed by alright $(27.78 \%)$ and excellent $(7.14 \%)$. Majority of rural women perceived as alright $(27.78 \%)$ followed by good $(21.60 \%)$ and excellent (4.32\%). Relatively higher proportion of rural women $(13.58 \%)$ than tribal women $(3.97 \%)$ felt that the follow up visits of health workers were not satisfactory. The differences between tribal and rural respondents were significant $(\mathrm{p}<0.001)$. It was enquired in the key-informant interviews about whether health workers assist the villagers to go to PHC or hospital to get family planning services. In some cases, the health workers take care of bringing people to PHC and get the operation done. They visit the family till the wounds are healed and stitches are removed. This care was relatively better serious and health workers took seriously in tribal areas, where as in rural area; people do not depend much on health workers. Even though they get services in PHC, they go themselves without the assistance of health worker.

\section{DISCUSSION}

In India, family planning services had become a part of primary health care system. Sufficient inputs and resources in family planning are required to achieve significant fertility decline. The present study assessed one of the components of the family planning service, provided by the primary health care system. The national family welfare programme in India has traditionally sought to promote responsible and planned parenthood through voluntary and free choice of family planning methods best suited to individual acceptors (Ministry of Health and Family Welfare, 1998). However, Simmons (1992) opined that contraceptive behaviour reflects the interaction of demand, supply and subjective constraints related to its access. Social, economic and cultural/ ideational factors influence the demand-supply dyad and through some decision-making process couples make a "rational" and "conscious choice" to adopt contraception (Coale, 1973). In the present study, current contraception users were more among rural than tribal areas. The predominant contraception method among both tribal and rural areas was female sterilization, i.e., tubectomy, as seen across other parts of the country. Traditional methods of contraception were less known than modern methods (International Institute for Population Sciences and ORC Macro, 2000). Similarly birth spacing methods have also been used by a very small number of people. These results suggest that despite the increased emphasis on contraceptive choice and on spacing methods in the government programmes, female sterilization continues to dominate the method mix and spacing methods still account for only a negligible amount of contraceptive use. 
Local PHC provides the family planning services, followed by other government health institutions and private institutions. It is known from other studies also that family planning services in Andhra Pradesh are provided primarily through a network of PHCs in rural and tribal areas (Retherford and Ramesh, 1996; Srinivasan and Mohanty, 2004). Some times these people get these services form health institutions located in urban areas. The services provided by private hospitals and nongovernmental organizations are also important. Sterilizations and IUD insertions are carried out mostly in government hospitals and PHCs. Sterilization camps, organized from time to time, also provide contraception services, particularly the permanent sterilization. Modern spacing methods such as IUD, pill, and condom are available through the government as well as private sectors. The quality of pre and post contraception care among the community is very important and it determines the acceptance of contraception by the community at large. In the present study, perceptions of the community on post-contraception care were not at desirable levels. Studies reported the occurrence of varied problems after sterilization (Gupte, 1994). The study of gynaecological morbidity in rural Maharashtra showed a significant association between contraceptive use and subsequent gynaecological problems (Bang et al., 1989). And in 13 centres all over the country, the principal adverse effects of the 11,688 tubectomised women were menstrual abnormalities, psychological sequelae, infections, keloid formation, incisional hernia, scar endomitriosis, dyspareunia and dysmenorrhea (Indian Council of Medical Research, 1982). This is unlike male sterilization, which may be generally trouble free. These findings emphasise the continuing need to strengthen postoperative care and counselling for sterilization acceptors. However, the present study on the postcontraceptive services indicated that the services were not up to the expected in both tribal and rural areas. In choosing between government and private services and practitioners, better off people tend to favour private sector treatment, since competence is often associated with cost (World Bank, 1996), and it is noticed even for contraceptive services. Thus, the centralized top-down planning of healthcare services could not facilitate the tribal and rural people to articulate needs for healthcare services. Hence, community health need assessment has to be made. Reorientation of the attitude of the health personnel has to be attempted to build confidence among the community. Therefore, training or orientation of these personnel for inculcating sense of responsibility towards patient care with more human touch is very essential to achieve higher utilization levels.

\section{REFERENCES}

Bang, R.A., A.T. Bang, M. Baitule, Y. Choudhary, S. Sarmukkadam and O. Tale. 1989. "High prevalence of gynaecological diseases in rural Indian women." Lancet, 1 (8629): 85-88.

Coale, A.J. 1973. "Age composition in the absence of mortality and in other odd circumferences." Demography, 10(4): 537-542.

Gupte, M. 1994. "Women's experience with family planning." Health for the Millions, 2(3): 33-36.

Hudelson, P. 1994. Qualitative Research for Health Programmes. No. WHO/MNH/PSF/94.3 Rev. 1. Geneva: World Health Organisation.

Indian Council of Medical Research. 1982. Collaborative Study on Sequelae of Tubal Sterilization. New Delhi: Indian Council of Medical Research.

Lengeler, C., H. Mashinda, D. de Savigny, P. Kilima, D. Morona, M. Tanner. 1991. "The value of questionnaires aimed at key informants, and distributed through an existing administrative system, for rapid and cost-effective health assessment." World Health Statistics Quarterly, 44(3): 150-159.

Ministry of Health and Family Welfare. 1998. Family Welfare Programme in India: Year Book, 199697. New Delhi: Department of Family Welfare, Ministry of Health and Family Welfare.

International Institute for Population Sciences and ORC Macro. 2000. National Family Health Survey (NFHS-2) 1998-99 India. Mumbai: International Institute for Population Sciences.

Padmadas, S.S., I. Hutter and F. Willekens. 2004. "Compression of women/s reproductive spans in Andhra Pradesh, India." International Family Planning Perspectives, 30(1): 12-19.

Pelto, P.J. and G.H. Pelto. 1978. Anthropological Research: The Structure of Enquiry. Cambridge: Cambridge University Press.

Retherford, R.D. and B.M. Ramesh. 1996. "Family and contraceptive use in Tamil Nadu, Andhra Pradesh and Uttar Pradesh." National Family Health Survey Bulletin, 3: 1-4.

Simmons, G.B. 1992. "Supply and demand, not supply vs. demand: appropriate theory for the study of efforts of family planning programmes on fertility", (Pp. 59-77). in J.F. Phillips and J.A. Ross (eds.), Family Planning Programmes and Fertility. Oxford: Claredon Press.

Spradley, J.P. 1979. The Ethnographic Interview. New York: Holt, Rinehart and Winston.

Srinivasan, K. and S.K. Mohanty. 2004. "Health care utilization by source and levels of deprivation in major states of India: findings from NFHS-2." Demography India, 33 (2): 107-126.

World Bank. 1996. Improving Women's Health in India. Washington DC: World Bank. 